\author{
А. А. Мешков, С. А. Афонский \\ Российский экономический университет имени Г. В. Плеханова, \\ Москва, Россия
}

В статье авторами обосновывается необходимость в современных условиях активного включения в состав коммуникаций с потребителем эстетической (чувственной) составляющей. Дается анализ современного состояния этой темы в научной литературе, показано использование на практике теоретических наработок ученых, рассматриваются конкретные примеры из мировой практики. Для результативного использования эмоций и восприятий потребителей в управлении маркетингом в целом, а также формирования предложения товаров и услуг следует наряду с маркетинговыми исследованиями, которые обычно проводятся для выяснения отношения потенциальных покупателей к предлагаемым базовым потребительским характеристикам, также протестировать продукт или услугу на ожидаемое эмоциональное восприятие. В результате анализа научной разработки данной темы отмечены объективные предпосылки для продолжения и углубления активных исследований в этом направлении. Актуальность исследования данной проблемы следует из необходимости усиления аффективного (эмоционального) элемента в маркетинге. Добавление к потребительской ценности эмоциональной составляющей может дать ощутимое преимущество для продвижения новых и обновления образа существующих товаров и услуг, и даже целых брендов.

Ключевые слова: ценностные предложения, эстетическая составляющая, дополнительные резервы конкурентоспособности, инструмент конкуренции, эмоциональные восприятия, экономика впечатлений, положительные эмоции, потребительская ценность.

\title{
COMPETITIVENESS MANAGEMENT BASED ON FACTORS OF CUSTOMER PERCEPTION OF GOODS AND SERVICES
}

\author{
Alexey A. Meshkov, Sergey A. Afonsky \\ Plekhanov Russian University of Economics, \\ Moscow, Russia
}

The authors of the article showed the necessity in today's conditions to include esthetic (sensual) component in communications with customers. The current standing of the subject in academic literature is depicted, practical use of scientists' theoretical achievements is shown and concrete examples from world practice are investigated. To use effectively customer emotions and perception in marketing management in general and in shaping goods and services offer it is needed together with marketing research, which is usually done in order to find out the attitude of potential customers to basic customer characteristics being offered to test product or service on expected emotional perception. As a result of the subject analysis the authors pointed out to objective preconditions for further and deeper research in this direction. Topicality of this problem researching follows from the necessity to strengthen the emotional element in marketing. Adding the emotional component to customer value can provide a serious advantage for promoting new goods and services and renewing the image of existing ones and brands as a whole.

Keywords: value offers, esthetic component, extra reserves of competitiveness, competitive tool, emotional perception, economy of impression, positive emotions, customer value. 


\section{Введение}

$\mathrm{B}$ ысокая насыщенность рынка близкими по назначению и качеству товарами и услугами, ограниченность использования методов ценового продвижения со всей очевидностью выдвигают перед маркетологами проблему поиска более эффективных методов и средств формирования ценностных предложений для потребителей, расширения круга факторов привлекательности и вовлечения дополнительных резервов конкурентоспособности товарных предложений компании. Проблема состоит в необходимости разработать способ представления товара или услуги, который был бы более убедительным, чем формат нынешних коммуникаций.

Такой резерв, по нашему мнению, лежит в более эффективном использовании эмоциональной (чувственной) составляющей ценностного предложения, которая способствует позитивному потребительскому восприятию, модифицирует способ использования товаров и услуг, реально может служить уникальным инструментом конкуренции в различных рыночных условиях. Эмоциональная составляющая ценностного предложения является эффективным критерием позиционирования и фактором рыночного продвижения товарных марок, создания и управления товарными марками на основе мотивов потребительского поведения. Потребители, уставшие от стандартизированной продукции, стремятся получить товар или услугу, созданную специально для них, соответствующую их внутреннему миру. В настоящее время все более продуктивными представляются идеи развития экономики впечатлений, ориентированной на эмоциональные восприятия потребительских ценностей.

По сравнению с поведенческими маркетинговыми исследованиями гораздо меньше известно о роли эмоций в поведении потребителей. Вместе с тем эмоции и впечатления занимают одно из центральных мест в действиях как потребителей, так и маркетинг-менеджеров. Актуальность исследования этой проблемы следует из необходимости усиления аффективного (эмоционального) элемента в маркетинге, поскольку существующая доступность и разнообразие информационного потока при выборе товара или услуги не отличаются сущностным разнообразием, а товары, производящиеся в одной и той же технологической среде, становятся функционально схожими.

\section{Состояние научной проработанности проблемы}

Вопросы использования эмоций и впечатлений в маркетинге впервые были рассмотрены в статье Р. Багоцци, М. Гопинат и П. У. Найер [11]. Авторы убедительно показали важность и необходимость более глубокого исследования эмоциональной составляющей в маркетинге, утверждая, что эмоции присутствуют на всем протяжении как процесса управления маркетингом, так и принятия решения о покупке потребителем. Они влияют на восприятие информации о товаре, принятие решений о покупке, посредничают в откликах на убедительные призывы продавцов, формируют целенаправленное поведение участников обмена, служат целями и мерами удовлетворенности потребителей.

Авторы монографии Б. Дж. Пайн II и Дж. Х. Гилмор [9] заявляют о зарождении нового направления в экономике - экономики впечатлений, ориентированной на чувственные восприятия потребителя. В монографии рассматриваются принципы успешной постановки впечатлений, театральные приемы, которые можно использовать при выведении товаров и услуг на потребительский рынок.

Тем не менее мы только начинаем понимать роль эмоций и впечатлений в маркетинге. В этой связи стоит отметить большое внимание, которое уделяется весьма эффективному инструменту повышения потребительской ценности - массовой персонализации, а также различным формам уместной потребительской уступ- 
ки. Своеобразное отделение впечатлений от услуг в деятельности компании открывает перед ней новые возможности для экономического роста, как в свое время признание услуг в качестве отдельного предложения привело к появлению нового типа экономики услуг на фоне ограниченных возможностей развития производственной базы [9].

В статье Дж. Биркиншоу, Д. Лян-Хун Кэ, Э. де Диего «Великий китайский замысел: четыре урока инноваций от WeChat» [2] на примере работы популярного китайского мессенджера WeChat обсуждаются возможности разных подходов к проектированию и продвижению ценностных предложений: дизайн-мышления и великого замысла. Авторы показывают очевидные преимущества второго подхода и формулируют основные принципы его действия, среди которых выделяется следующий: «Создавайте не коммерческий продукт, а произведение искусства» [2]. Кроме того, утверждается, что руководителю необходимо взять инициативу разработки рекламного образа компании на себя, учитывая свой жизненный опыт, профессионализм, подчиняясь своему внутреннему голосу, при этом не подстраиваясь под вкусы и часто сиюминутные желания толпы, а создавая действительно что-то важное, новое, красивое, нравственное, может быть, даже вечное. Важно прислушиваться к пользователям избирательно [2].

Руководство одной из крупнейших промышленных компаний «Газ де Франс» (третий перевозчик сжиженного газа в мире) неожиданно (по отношению к здравому смыслу) приняло решение придать образу компании нежность и женственность, создав логотип в виде изогнутого женского тела. При этом не проводились опросы и фокус-группы, так как, по мнению руководства, тестирование убивает креатив. Это новшество оказалось весьма удачным, а сотрудники компании сказали, что именно таким и хотели видеть образ своей компании [2]. Конечно, такие обновления бренда стоит делать только в том случае, когда есть полная уверенность в правильности инноваций, хотя риск существует всегда. Однако уточняется, что великий замысел дает больше шансов на успех в условиях высокой неопределенности, а также там, где потребности пользователей неизвестны или потенциально поддаются влиянию.

Дж. Корст и К. Уитлер в работе «Почему подход Джобса работает не для всех» [8] отстаивают подход дизайн-мышления, ориентированный на изучение потребностей пользователей, рекомендуя при разработке и представлении продукта пользоваться методом «извне - внутрь». Можно выделить три основных шага, которые должны учитывать руководители для успешного использования этого подхода: «повысить роль маркетинга в формировании будущих продуктов и инноваций; управлять по принципу «извне - внутрь»; ориентироваться не на всех, а на целевых клиентов» [8]. Только в этом случае, по мнению авторов, компания может создать конкурентоспособный продукт, удобный и интуитивно понятный для пользователей. Можно было бы назвать этот принцип игрой по правилам. Действительно, такой подход выглядит разумным, следующим логике жизни. Однако эта философия здравого смысла, когда все взвешено и просчитано, позволяет создавать нечто срединное. Как сказал известный персонаж популярного фильма «Ирония судьбы, или С легким паром» Е. Лукашин, обращаясь к своему оппоненту: «Великое вам не по плечу». При этом стоит отметить, что конкретные обстоятельства жизненного цикла компании и внешнее окружение диктуют тот или иной подход, как это случается в любом виде организационной деятельности человека. Как известно, иногда жизненно необходимо отступать или пить горькое лекарство.

В статье Дж. Вессел, Э. Альтендорф, М. Швальм, Й. Канполат, К. Бургхардт, Ф. Флемиш «Самостоятельное подталкивание: системная концепция взаимодействия человека с машиной» [3] обращается 
внимание на тот факт, что пользователи иногда испытывают трудности при обращении с техническими средствами, поскольку то, что они должны сделать в определенный момент, может отличаться от того, что, по их восприятию, они должны делать исходя из прошлого опыта. В этой концепции сначала оценивается желание человека, а затем предлагаются вспомогательные механизмы, с тем чтобы направлять людей к их собственным целям. Концепция самостоятельного выбора позволяет создать ценностное предложение, ориентированное на пользователя, а не на разработчика.

В известной книге «Новая поведенческая экономика. Почему люди нарушают правила традиционной экономики и как на этом заработать» Р. Талер показывает, почему люди нарушают предписанные правила поведения и как можно заработать на знании особенностей человеческого восприятия и суждения, формирования предпочтений и поведенческих эвристик, влияния этих особенностей на принимаемые ими решения [10].

Эксперименты Д. Канемана и А. Тверски по созданию кадров подчеркнули, что традиционные модели принятия решений не могут полностью объяснить поведение при принятии решений. Из пошатнувшейся модели рационального выбора родилась теория перспектив, т. е. лица, принимающие решения, не всегда выбирают результат с наибольшей полезностью [6].

Классическая эвристика, первоначально предложенная Канеманом и Тверски, является эвристической привязкой и корректировкой. Эта эвристика предполагает, что суждения людей чувствительны к якорям, которые, как правило, являются первыми частями информации, предоставляемой лицам, принимающим решения. Они несоразмерно влияют на процессы и результаты принятия решений. Авторы продемонстрировали, что участники были чувствительны к ранее представленным числам, что вызывало эффект привязки, кото- рый затем корректировался при принятии окончательного решения.

В. Терзиев и Д. Канев в статье «Поведенческая экономика: развитие, состояние и перспективы» указывают на то, что мозг является мощным инструментом для оценки и принятия решений. Однако это очень неэффективно. Мозг не может установить в одновременной работе более двух процентов своих нейронов. Если их количество превышает этот предел, запасы использованного «топлива» (глюкозы) истощаются настолько быстро, что человек теряет сознание. В результате этих ограничений каждая экономия интеллектуальных усилий и времени очень желательна. Вот почему, когда это возможно, сознание всегда действует интуитивно и автоматически обрабатывает чувственные сигналы, а также информацию о прибылях и убытках, богатстве, престиже и социальных иерархиях [13].

В исследовании К. Могильнер, Дж. Аакер, С. Д. Камвар «Как счастье влияет на выбор» говорится, что счастье определяется как состояние благополучия и удовлетворенности; приятное или удовлетворяющее переживание [12]. Опираясь на это определение, некоторые исследователи рассматривают счастье как единственное в своем роде, одно и то же для всех людей [5]. Другие ученые предполагают, что счастье в высшей степени субъективно, что его понимание у каждого человека разное [4]. Третья часть исследователей повествует, что существует несколько типов счастья, которые меняются в разных культуpax и возрастных категориях [1]. Эта группа ученых основывается на двух типах положительных эмоций, которые могут быть восприняты каждым субъектом как счастье. Первый тип включает в себя возбуждение, восторг и энтузиазм и был определен как позитивный аффект, который находится на высоком уровне возбуждения. Второй тип включает в себя спокойствие, миролюбие и безмятежность и был определен как положительный эффект, который находится на низком уровне воз- 
буждения. Поэтому для достижения нужного результата в целях продвижения товара или услуги следует учитывать не только необходимость создания положительных эмоций у потенциальных потребителей, но и особенности той или иной целевой аудитории (культурные коды, предпочтения целевых аудиторий и др.).

В статье «Подробное руководство по эмоциональному маркетингу» Н. Коленда дает интересный анализ тем широким возможностям, которые раскрывает умелое использование эмоционального состояния человека для позиционирования, продвижения и реализации товаров и услуг. Об этом свидетельствует перечень затрагиваемых тем: эмоциональный маркетинг - что это; что такое эмоции; почему люди испытывают эмоции; какие эмоции влияют на решения, которые мы принимаем; когда использовать эмоциональные призывы; какие бывают типы эмоций; какие эмоции вы должны настроить; как вызывать эмоции [7]. Одно можно сказать с убежденностью: чувство симпатии, приятия, внутренней близости, ощущение, что это твое (твоя вещь, твой магазин, твой человек и т. д.), должно органично состыковываться со своим менталитетом, своей системой ценностей.

\section{Задачи тестирования восприятий потребителей}

Использование эмоциональных восприятий в маркетинге требует предварительных измерений и оценки их влияния наряду с другими инструментами маркетинга. Маркетологи, как правило, используют эмпирический подход к измерению результатов воздействия инструментов и полагаются на самоотчеты респондентов, принимающих участие в исследованиях, которые затем используются для получения искомых статистических выводов.

Для результативного использования эмоций и восприятий потребителей в управлении маркетингом в целом, а также формирования предложения товаров и услуг следует наряду с маркетинговыми исследованиями, которые обычно проводятся для выяснения отношения потенциальных покупателей к предлагаемым базовым потребительским характеристикам, также протестировать продукт или услугу на ожидаемое эмоциональное восприятие.

В процессе тестирования необходимо выяснить:

- какой вклад вносят эмоции в этапы принятия решения о покупке;

- каким образом эмоции влияют на кодирование, форму хранения, поиск и восприятие информации о продукте;

- какие основные формы эмоционального восприятия потребителей могут служить в качестве маркетинговых стимулов;

- какие элементы маркетинговой среды формируют эмоции, способствующие принятию позитивных решений потребителем;

- как потребители контролируют свои эмоции в процессе выбора и совершения покупки;

- как различные эмоции связаны друг с другом;

- является ли удовлетворенность потребителей уникальным явлением или результатом положительных эмоций.

Решение вышеперечисленных задач будет способствовать усилению аффективного (эмоционального) элемента в маркетинге.

\section{Список литературы}

1. Аакер Дж., Смит Э. Эффект стрекозы: все об улетных промокампаниях в социальных сетях. - М. : Альпина Бизнес Букс, 2011.

2. Биркиншоу Дж., Лян-Хун Кэ Д., де Диего Э. Великий китайский замысел: четыре урока инноваций от WeChat // Harvard Business Review. - 2020. - 15 января. - URL: https:// hbr-russia.ru/innovatsii/upravlenie-innovatsiyami/820571 
3. Вессел Дж., Альтендорф Э., Швальм М., Канполат Й., Бургхардт К., Флемиш Ф. Самостоятельное подталкивание: системная концепция взаимодействия человека с машиной. London : Springer Nature, 2019.

4. Гилберт Д. Спотыкаясь о счастье $=$ Stumbling on Happiness. - M. : Альпина Паблишер, 2015.

5. Динер Э., Динер М. Кросс-культурные корреляты удовлетворенности жизнью и самооценки / / Журнал личности и социальной психологии. - 1995. - № 68 (4). - С. 653-663.

6. Канеман Д., Тверски А. Рациональный выбор, ценности и фреймы // Психологический журнал. - 2003. - Т. 24. - № 4. - С. 31-43.

7. Коленда H. Подробное руководство по эмоциональному маркетингу. - URL: https://www.nickkolenda.com/emotional-marketing/

8. Корст Дж., Уитлер К. Почему подход Джобса работает не для всех // Harvard Business Review. - 2020. - 17 января. - URL: https://hbr-russia.ru/innovatsii/upravlenieinnovatsiyami/820752

9. Пайн II Б. Дж., Гилмор Дж. Х. Экономика впечатлений. Работа - это театр, а каждый бизнес - сцена. - М. : Вильямс, 2005.

10. Талер Р. Новая поведенческая экономика. Почему люди нарушают правила традиционной экономики и как на этом заработать. - М. : Эксмо, 2018.

11. Bagozzi R. P., Gopinath M., Nyer P. U. The Role of Emotions in Marketing // Journal of the Academy of Marketing Science. - 1999. - Vol. 27. - N 2. - P. 184-206. - URL: http:// dx.doi.org/10.1177/0092070399272005

12. Mogilner C., Aaker J., Kamvar S. D. How Happiness Affects Choice // Journal of Consumer Research. - 2012. - Vol. 39. - N 2. - P. 429-443.

13. Terziev V., Kanev D. Behavioral Economics: Development, Condition and Perspectives // International E-Journal of Advances in Social Sciences. - 2017. - Vol. 3. - Issue 8. - P. 413-423.

\section{References}

1. Aaker J., Smith E. Effekt strekozy: vse ob uletnykh promokampaniyakh v sotsialnykh setyakh [Dragon-Fly Effect: Ideas about Cool Promo-Campaigns in Social Networks]. Moscow, Alpina Biznes Buks, 2011. (In Russ.).

2. Birkinshow Dzh., Lyan-Khun Ke D., de Diego E. Velikiy kitayskiy zamysel: chetyre uroka innovatsiy ot WeChat [Great Chinese Project: Four Lessons of Innovation given by WeChat]. Harvard Business Review, 2020, January 15. (In Russ.). Available at: https://hbr-russia.ru/ innovatsii/upravlenie-innovatsiyami/820571

3. Vessel J., Altendorf E., Shvalm M., Kanpolat Y., Burgkhardt K., Flemish F. Samostoyatelnoe podtalkivanie: sistemnaya kontseptsiya vzaimodeystviya cheloveka $\mathrm{s}$ mashinoy [Self-Determination of Pushing: System Concept of Interaction between Man and Machine]. London, Springer Nature, 2019. (In Russ.).

4. Gilbert D. Spotykayas o schaste = Stumbling on Happiness. Moscow, Alpina Pablisher, 2015. (In Russ.).

5. Diner E., Diner M. Kross-kulturnye korrelyaty udovletvorennosti zhiznyu i samootsenki [Cross-Cultural Correlations of Life Satisfaction and Self-Appraisal]. Zhurnal lichnosti $i$ sotsialnoy psikhologii [Journal of Personality and Social Psychology], 1995, No. 68 (4), pp. 653663. (In Russ.).

6. Caneman D., Tversky A. Ratsionalnyy vybor, tsennosti i freymy [Rational Choice, Values and Frames]. Psikhologicheskiy zhurnal [Psychological Journal], 2003, Vol. 24, No. 4, pp. 31-43. (In Russ.). 
7. Kolenda N. Podrobnoe rukovodstvo po emotsionalnomu marketing [Detailed Guidance on Emotional Marketing]. (In Russ.). Available at: https://www.nickkolenda.com/emotionalmarketing/

8. Korst J., Witler K. Pochemu podkhod Dzhobsa rabotaet ne dlya vsekh [Why doesn't Job's Approach Work for Everyone]. Harvard Business Review, 2020, January 17. (In Russ.). Available at: https://hbr-russia.ru/innovatsii/upravlenie-innovatsiyami/820752

9. Pine II B. Dzh., Gilmor J. H. Ekonomika vpechatleniy. Rabota - eto teatr, a kazhdyy biznes - stsena [Economy of Impression. Work is a Theater and each Business is a Scene]. Moscow, Williams, 2005. (In Russ.).

10. Taler R. Novaya povedencheskaya ekonomika. Pochemu lyudi narushayut pravila traditsionnoy ekonomiki i kak na etom zarabotat [New Behavioral Economy. Why People Break Rules of Traditional Economy and How you can Make Money on it]. Moscow, Exmo, 2018. (In Russ.).

11. Bagozzi R. P., Gopinath M., Nyer P. U. The Role of Emotions in Marketing. Journal of the Academy of Marketing Science, 1999, Vol. 27, No. 2, pp. 184-206. Available at: http:// dx.doi.org/10.1177/0092070399272005

12. Mogilner C., Aaker J., Kamvar S. D. How Happiness Affects Choice. Journal of Consumer Research, 2012, Vol. 39, No. 2, pp. 429-443.

13. Terziev V., Kanev D. Behavioral Economics: Development, Condition and Perspectives. International E-Journal of Advances in Social Sciences, 2017, Vol. 3, Issue 8, pp. 413-423.

\section{Сведения об авторах}

\section{Алексей Александрович Мешков \\ доктор экономических наук, профессор кафедры маркетинга РЭУ им. Г. В. Плеханова. \\ Адрес: ФГБОУ ВО «Российский экономический университет имени Г. В. Плеханова», 117997, Москва, Стремянный пер., д. 36. E-mail: Meshkov.AA@rea.ru}

\section{Сергей Александрович Афонский} член правления ОХГСИ Московского союза художников, член Правления Московского отделения ВТОО «Союз художников России», доцент кафедры рекламы, связей

с общественностью и дизайна РЭУ им. Г. В. Плеханова.

Адрес: ФГБОУ ВО «Российский экономический университет имени Г. В. Плеханова», 117997, Москва, Стремянный пер., д. 36.

E-mail: afonskysv@mail.ru

\section{Information about the authors}

\author{
Alexey A. Meshkov \\ Doctor of Economics, Professor \\ of the Department for Marketing \\ of the PRUE. \\ Address: Plekhanov Russian University \\ of Economics, 36 Stremyanny Lane, \\ Moscow, 117997, \\ Russian Federation. \\ E-mail: Meshkov.AA@rea.ru
}

\section{Sergey A. Afonsky}

OHGSI Board Member of the Moscow Union of Artists, Board Member of the Moscow Branch of VTOO 'The Union of Painters of Russia', Assistant Professor of the Department for Advertising, Public Relations and Design of the PRUE.

Address: Plekhanov Russian University of Economics, 36 Stremyanny Lane, Moscow, 117997, Russian Federation.

E-mail: afonskysv@mail.ru 